\title{
High periostin expression correlates with aggressiveness in papillary thyroid carcinomas
}

\author{
Cinzia Puppin ${ }^{1}$, Dora Fabbro ${ }^{2}$, Mariavittoria Dima ${ }^{1}$, Carla Di Loreto ${ }^{3}$, Efisio Puxeddu ${ }^{4}$, Sebastiano Filetti ${ }^{5}$, \\ Diego Russo ${ }^{6}$ and Giuseppe Damante ${ }^{1,2}$
}

\author{
${ }^{1}$ Dipartimento di Scienze e Tecnologie Biomediche, Università di Udine, Piazzale Kolbe 1, 33100 Udine, Italy \\ ${ }^{2}$ Azienda Ospedaliero-Universitaria 'S Maria della Misericordia' Udine, Udine, Italy \\ ${ }^{3}$ Dipartimento di Ricerche Mediche e Morfologiche, Università di Udine, Udine, Italy \\ ${ }^{4}$ Dipartimento di Medicina Interna, University of Perugia, Perugia, Italy \\ ${ }^{5}$ Dipartimento di Scienze Cliniche, Università di Roma 'la Sapienza', Roma, Italy \\ ${ }^{6}$ Dipartimento di Scienze Farmacobiologiche, Università di Catanzaro, Catanzaro, Italy \\ (Correspondence should be addressed to G Damante; Email: gdamante@makek.dstb.uniud.it)
}

\begin{abstract}
Periostin is a mesenchyme-specific gene product, which acts as an adhesion molecule during bone formation and supports osteoblastic cell line attachment and spreading. However, periostin expression is activated in a large variety of epithelial human tumors and correlates with their aggressiveness. Knowledge of expression of periostin in thyroid tumors is still scanty. The aim of the present work was to investigate periostin expression in differentiated neoplasms of the thyroid and to correlate it with several clinical and molecular features of these tumors. Periostin expression was evaluated by quantitative PCR and immunohistochemistry in normal thyroid tissues, papillary thyroid carcinomas (PTCs), follicular thyroid carcinomas (FTCs), and follicular adenomas (FAs). Periostin mRNA levels were also evaluated in several thyroid tumor cell lines. PTCs show mean periostin mRNA levels significantly higher than corresponding normal tissues. In five PTCs, periostin mRNA values were at least 30-fold higher
\end{abstract}

than corresponding normal tissues. Conversely, mean periostin mRNA levels of FTCs and FAs were similar to those of normal tissues. Consistent with mRNA studies, periostin was detectable by immunohistochemistry in cancerous epithelial cells only in several cases of PTCs but not in normal tissue, FTCs, and FAs. In PTCs, periostin mRNA levels positively correlate with extrathyroidal invasion, distant metastasis, and higher grade staging. A negative correlation between periostin and expression of some markers of the thyroid-differentiated phenotype (thyroglobulin, thyrotropin receptor) was also present in the PTCs. These results indicate that an increase in periostin gene expression is present in several PTCs, in which it appears as a marker of aggressiveness. Experiments in thyroid tumor cell lines indicate that high levels of periostin mRNA are due, at least in part, to the increase in periostin promoter activity.

Journal of Endocrinology (2008) 197, 401-408

\section{Introduction}

Loss of the differentiated phenotype is a main characteristic of the neoplastic cell. In many cell types, it occurs as a result of both loss of expression of differentiation markers and acquisition of phenotypic characteristics of a distinctly different cell type (transdifferentiation; Zhang \& Xie 1994). In the thyroid follicular cell (TFC), the reduction/loss of expression of genes devoted to the synthesis of thyroid hormones occurring during transformation has been extensively described (Brabant et al. 1991, Ros et al. 1999, Schlumberger et al. 2007). Thus, sodiumiodide symporter (NIS), thyroperoxidase (TPO), thyroglobulin $(\mathrm{Tg})$, and thyrotropin receptor (TSHR) gene expressions are progressively reduced or lost when the thyrocyte acquires more aggressive characteristics (Zhang \& Xie 1994). Moreover, even expression of thyroid-specific transcription factors, such as
TTF-1, HEX, and PAX8, is also down-regulated during transformation of the TFC (Fabbro et al. 1994, Damante et al. 2001). Transdifferentiation may occur in thyroid cancer. Recently, evidence of epithelial-to-mesenchymal transition (EMT) has been reported in papillary thyroid carcinoma (PTC) and has been related to their aggressive behavior (Vasko et al. 2007). Accordingly, various signaling pathways involved in EMT including integrin, MET, and transforming growth factor- $\beta$ have been shown to be altered in thyroid tumor cells (Huber et al. 2005), as well as expression of some genes such as fibronectin and vimentin considered as a hallmark of EMT (Vasko et al. 2007).

Among the mesenchymal-specific proteins aberrantly expressed in various tumors of epithelial origin, an increasing interest is emerging regarding periostin. It is a mesenchymespecific gene product, originally identified as a gene expressed in 
mouse osteoblasts (Takeshita et al. 1993), which acts as an adhesion molecule during bone formation and supports osteoblastic cell line attachment and spreading (Horiuchi et al. 1999). Accordingly, it has been shown that periostin is a ligand for $v \beta 3$ and $v \beta 5$ integrins inducing integrin-dependent cell adhesion and motility (Gillan et al. 2002). Studies on periostin expression in human cancers have demonstrated that its expression is increased in a large variety of tumors including breast, colon, bladder, and non-small cell lung cancer (Kudo et al. 2007). In most situations, high periostin expression correlated with tumor aggressiveness (Sasaki et al. 2001, 2003, Shao et al. 2004, Kudo et al. 2007). Moreover, it has been shown that periostin promotes metastatic growth by augmenting cell survival through the Akt/protein kinase B pathway (Bao et al. 2004). Thus, expression of periostin in neoplasms of epithelial origin could be considered as a phenomenon of transdifferentiation that contributes to the tumor progression.

Knowledge of periostin expression in thyroid tumors is still scanty. The only available data are those reported by Fluge et al. (2006). These authors, using cDNA microarrays and real-time PCR to compare a small number of differentiated and aggressive PTCs, showed that periostin is highly expressed in some aggressive PTCs.

The aim of the present work was to investigate periostin expression in differentiated neoplasms of the thyroid and to correlate it with several clinical and molecular features of these tumors.

\section{Materials and Methods}

\section{Patients and tissues}

Surgical specimens of 7 non-consecutive sporadic thyroid follicular adenomas (FAs), 12 follicular thyroid carcinomas (FTCs), and 52 PTCs were analyzed. Normal tissues originating from the non-neoplastic tissue of all FAs and FTCs and 40 out of 52 PTCs were also analyzed. The tissues were snap frozen and stored at $-80^{\circ} \mathrm{C}$ until use. Patients' charts were reviewed to define the clinical features of each case. All tumors were histologically diagnosed and, when possible, staged according to the criteria of the American Joint Committee on Cancer (Greene et al. 2002). The study was approved by the local medical ethics committee. Before surgery, each study participant provided written informed consent to the collection of fresh thyroid tissue for genetic studies.

\section{Cell lines and transfections}

The ARO and FRO cells; BCPAP, TPC-1 and NPA cells; and WRO cells derived from human anaplastic thyroid carcinomas; PTC; and follicular thyroid cancer respectively, were grown as previously described (Russo et al. 2001).

Transfections were performed by Lipofectamine (Invitrogen) according to the manufacturer's instructions. The periostin promoter construct, Periostin563-Luc, was kindly donated by Prof Kudo (Oshima et al. 2002). The transfection efficiency was normalized by cotransfecting the Rous sarcoma virus-cloramphenicolacetyltransferase (RSV-CAT) plasmids, which contains the RSV promoter, linked to the CAT gene. The cells were harvested $48 \mathrm{~h}$ after transfection and the cell extracts were prepared by a standard freeze and thaw procedure. CAT protein levels were measured by ELISA method (AmershamPharmacia Biotech). Luciferase activity was measured by a standard chemiluminescence procedure.

\section{Gene expression, immunohistochemistry, and detection} of $B-R A F$ mutations

Quantitative PCR analysis of periostin mRNA expression was performed as previously described (Puppin et al. 2005). Briefly, total RNA from cell lines was extracted with RNeasy protect mini kit (Qiagen). One microgram of total RNA was reverse transcribed to single-strand cDNA using random exaprimers and $200 \mathrm{U}$ MMLV reverse transcriptase (Invitrogen) in a final volume of $20 \mu \mathrm{l}$ at $42{ }^{\circ} \mathrm{C}$ for $50 \mathrm{~min}$ followed by heating at $70{ }^{\circ} \mathrm{C}$ for $15 \mathrm{~min}$. Real-time PCRs were performed using the ABI Prism 7300 Sequence Detection System (Applied Biosystems, Foster City, CA, USA). Oligonucleotide primers and probes for periostin were purchased from Applied Biosystems as Assays-on-Demand Gene Expression Products. Oligonucleotide primers and probes for the endogenous control $\beta$-glucuronidase are described by Beillard et al. (2003). A $25 \mu \mathrm{l}$ reaction mixture containing $5 \mu \mathrm{l}$ cDNA template, $12 \cdot 5 \mu \mathrm{l}$ TaqMan Universal PCR master mix (Applied Biosystems), and 1.25 $\mu$ primer probe mixture was amplified using the following thermal cycler parameters: incubation at $50{ }^{\circ} \mathrm{C}$ for $2 \mathrm{~min}$ and denaturation at $95^{\circ} \mathrm{C}$ for $10 \mathrm{~min}$, then 40 cycles of the amplification step (denaturation at $95^{\circ} \mathrm{C}$ for $15 \mathrm{~s}$ and annealing/extension at $60^{\circ} \mathrm{C}$ for $\left.1 \mathrm{~min}\right)$. The $\Delta \mathrm{CT}$ method, by means of the SDS software (Applied Biosystems), was used to calculate the mRNA levels. The PTC cell line, BCPAP, was used as the calibrator. Thus, periostin mRNA levels are always expressed as multiple or fraction of the BCPAP expression levels, considered arbitrarily as 1 .

Expression of NIS, apical iodide transporter (AIT-B), TPO, $\mathrm{Tg}$, and TSHR genes was evaluated by quantitative PCR as previously described (Durante et al. 2007).

$B-R A F$ mutations were identified by single-stranded conformation polymorphism screening of products obtained by RT-PCR amplification of exon 15 , and results were confirmed by means of sequence analysis (Puxeddu et al. 2004).

Dewaxed tissue sections of a different series of thyroid tumors, including $10 \mathrm{FAs}, 10 \mathrm{FTCs}$, and $10 \mathrm{PTCs}$, were analyzed by immunohistochemistry to search for expression of the periostin protein. Immunohistochemistry was performed using a rabbit polyclonal antibody (Biovendor Laboratory, Heidelberg, Germany) with a final dilution to 1:1500 and a polymer-based immunohistochemical detection system (Super Sensitive Polymer-HPR IHC Detection 
System BioGenex, San Ramon, CA, USA). Specificity of the immunohistochemical signal was controlled by omitting the primary antibody.

\section{Statistical analysis}

Correlations between periostin expression levels above or below the mean value of $41 \cdot 44$, and clinicopathological parameters were analyzed in all PTC patients unless otherwise indicated. We used the $t$-test to compare continuous variables and the $\chi^{2}$-test to determine $P$ values in $2 \times 2$ contingency tables. Moreover, the correlation between the two groups with periostin expression levels above or below the mean value of 41.44 and quantitative PCR results for NIS, AIT-B, TPO, Tg, and TSH-R gene expressions, obtained for 43 PTC patients of the studied cohort, were also analyzed by means of $t$-test. $P$ values of $<0 \cdot 05$ were considered significant.

\section{Results}

Periostin $m R N A$ levels in thyroid tumors

Periostin mRNA levels were evaluated by quantitative RT-PCR in 59 normal thyroid tissue, tumoral tissue of 52 subjects with PTC, 12 subjects with FTC, and 7 subjects with FA. Normal tissue specimens originate from the nonneoplastic thyroid tissue of 40 out of 52 subjects with PTC, all 12 subjects with FTC, and all 7 subjects with FA. Results are shown in Fig. 1(A). Papillary carcinomas show mean periostin mRNA values significantly higher than corresponding normal tissues $(41 \cdot 44 \pm 57 \cdot 85$ vs $3 \cdot 73 \pm 3 \cdot 32$, $P<0 \cdot 0001)$. Among PTC subjects in which both tumoral and normal tissues were analyzed, 31 out of 40 show periostin mRNA levels higher than the normal counterparts. In five PTCs, periostin mRNA values were at least 30-fold higher than the corresponding normal tissues. In 7 out of 12 FTCs, periostin mRNA levels were higher than the corresponding normal tissues. However, mean periostin mRNA values were not significantly different between FTCs and all normal tissues $(3.37 \pm 2.79$ vs $3.73 \pm 3.32, P=0.68)$. These data indicate that periostin gene expression is heterogeneous in differentiated thyroid carcinomas and only a subset of PTC expresses high periostin mRNA levels. In all seven cases of FAs, periostin mRNA levels in the tumor were higher than the corresponding normal tissue. However, as observed in FTCs, mean periostin mRNA values were not significantly different from that observed in the normal tissues $(5 \cdot 88 \pm 4 \cdot 36$ vs $3 \cdot 73 \pm 3 \cdot 32, P=0 \cdot 15)$. Figure $1(\mathrm{~B})$ shows the relationship between periostin levels detected in the paired normal and PTC tissues: it is clear that the increase in periostin mRNA levels observed in tumor tissues is not dependent on the periostin mRNA levels present in normal tissues.
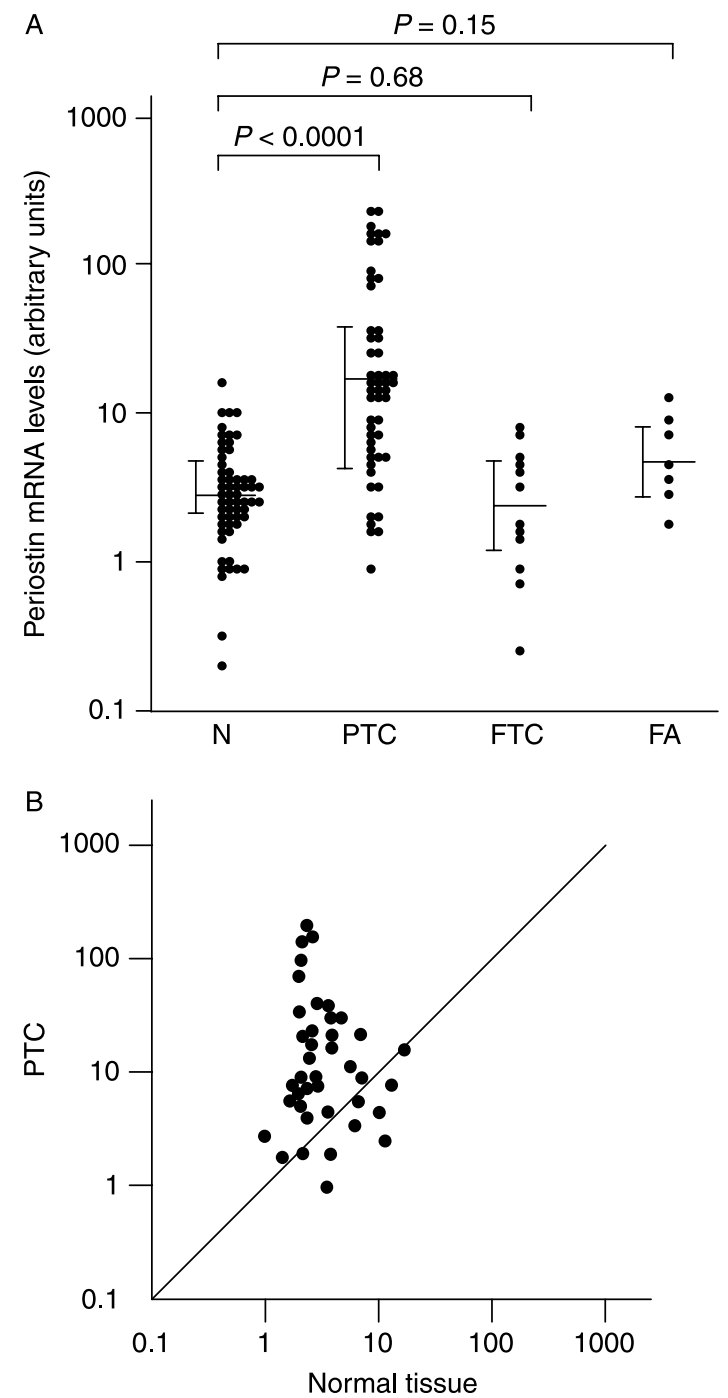

Figure 1 (A) Periostin mRNA levels in normal, papillary carcinoma, follicular carcinoma, and follicular adenoma tissues. Each dot represents periostin mRNA levels in a single specimen and is the mean value of three independent determinations. N, normal; PTC, papillary carcinomas; FTC, follicular carcinomas; and FA, follicular adenomas. In each group, the horizontal bar represents the median value. The vertical bar indicates the $75^{\circ}-25^{\circ}$ percentile range.

(B) Relationship of the periostin mRNA levels in 40 cases of paired normal and PTC tissues. Each dot indicates the periostin mRNA levels in a single normal tissue-PTC pair. The straight line indicates the equality of periostin mRNA levels between normal tissue and PTC pairs. Thus, dots above and below the straight line indicate cases in which the periostin mRNA levels in PTCs are higher or lower than normal tissues respectively.

\section{Periostin protein levels in thyroid tumors}

In order to test whether periostin was produced by epithelial tumor cells, a different cohort of PTCs (10 samples), FTCs (10 samples), FAs (10 samples), and normal thyroid tissues (10 samples) were subjected to immunohistochemical analysis 
with a periostin-specific antibody. No staining was observed in normal thyroid tissue and FA (Fig. 2A and B), while a diffuse cytoplasmic staining was observed in epithelial cells of four out of ten PTCs (Fig. 2C). Epithelial cells of FTCs were negative for periostin expression, although a weak cytoplasmic staining was rarely observed (Fig. 2D). Thus, only in a subset of PTCs, epithelial cells produce enough periostin to be revealed by immunohistochemistry. In order to correlate the expression of the periostin protein with the periostin mRNA levels, some PTCs were subjected both to immunohistochemistry and quantitative RT PCR. Figure 2E shows that all PTCs that were positive to immunohistochemistry, display periostin mRNA levels higher than those negative to immunohistochemistry.

\section{Correlation with clinical and molecular characteristics and $B-R A F$ mutation}

To verify the existence of a relationship between the expression levels of periostin mRNA and the aggressiveness of the tumors, the 52 PTC samples were divided into two groups with mRNA levels higher and lower than the mean value respectively and compared for a series of clinicopathological parameters.
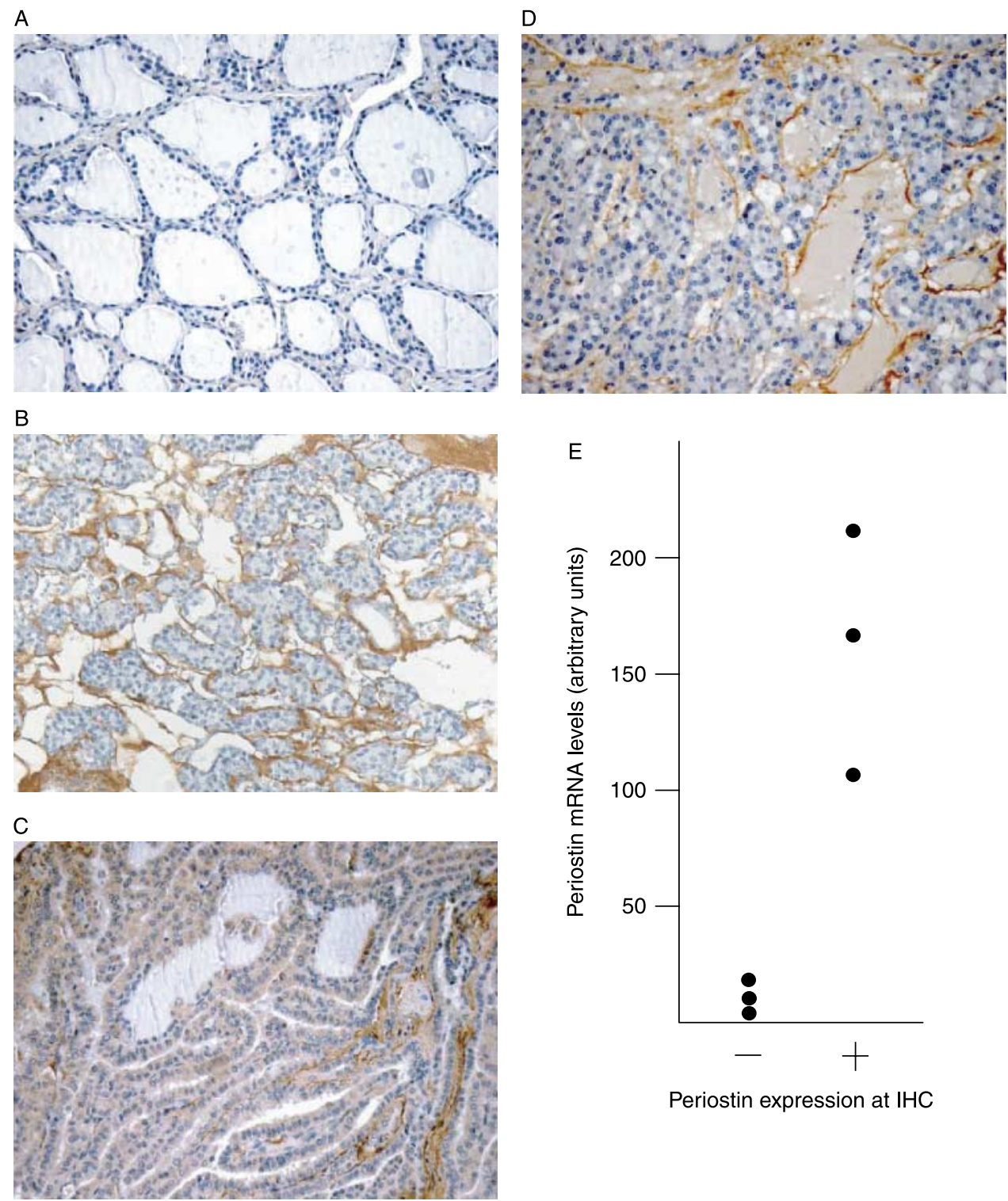

Figure 2 Immunohistochemical detection of periostin in normal thyroid and papillary carcinoma. The brown color indicates the periostin positivity. (A) Normal thyroid, (B) follicular adenoma,

(C) papillary thyroid carcinoma, and (D) follicular thyroid carcinoma. (E) Periostin mRNA levels in PTCs positive $(+)$ or negative $(-)$ at the periostin immunohistochemical detection. 
As shown in Table 1, a significant difference between the two groups was observed concerning the presence of extrathyroidal invasion, distant metastasis, and higher grade staging. Indeed, periostin mRNA higher levels matched with all these signs of a more aggressive phenotype of the tumors. This notion is confirmed when periostin is computed as a continuous (numerical) variable. In fact, Fig. 3 shows that in stage III+IV PTCs periostin protein levels are significantly higher than in stage I + II PTCs $(55 \cdot 77 \pm 58 \cdot 34$ vs $17 \cdot 38 \pm 35 \cdot 86, P=0 \cdot 010)$.

No relationship was detectable with the presence of B-RAF mutation (Table 1). Moreover, analysis of the clinicopathological characteristics of the 52 PTCs divided into two groups according to the presence of B-RAF mutation showed no association between $B-R A F$ mutation

Table 1 Associations between periostin expression levels and clinicopathologic and genetic characteristics of papillary carcinomas (PTCs)

\begin{tabular}{|c|c|c|c|}
\hline & $\begin{array}{l}\text { Periostin } \\
\text { expression }< \\
\text { mean }\end{array}$ & $\begin{array}{l}\text { Periostin } \\
\text { expression }> \\
\text { mean }\end{array}$ & $\boldsymbol{P}$ \\
\hline \multicolumn{4}{|c|}{ Characteristics } \\
\hline $\begin{array}{l}\text { Age at } \\
\text { diagnosis }^{a}\end{array}$ & $49 \cdot 8 \pm 17$ & $56 \cdot 2 \pm 15 \cdot 1$ & $0 \cdot 23$ \\
\hline Tumor size & $2 \cdot 01 \pm 0 \cdot 87$ & $2 \cdot 25 \pm 0 \cdot 87$ & $0 \cdot 43$ \\
\hline \multicolumn{4}{|l|}{ Sex } \\
\hline Male & 12 & 3 & \multirow[t]{2}{*}{$0 \cdot 59$} \\
\hline Female & 27 & 10 & \\
\hline \multicolumn{4}{|l|}{ Multicenter ${ }^{c}$} \\
\hline Yes & 18 & 3 & \multirow[t]{2}{*}{$0 \cdot 26$} \\
\hline No & 21 & 8 & \\
\hline \multicolumn{4}{|c|}{ Extrathyroidal invasion $^{\mathrm{a}}$} \\
\hline Yes & 11 & 7 & \multirow[t]{2}{*}{$0 \cdot 04$} \\
\hline No & 28 & 5 & \\
\hline \multicolumn{4}{|c|}{ Lymph node metastasis $^{\mathrm{a}}$} \\
\hline Yes & 19 & 6 & \multirow{2}{*}{$0 \cdot 73$} \\
\hline No & 20 & 5 & \\
\hline \multicolumn{4}{|c|}{ Distant metastasis $^{\mathrm{d}}$} \\
\hline Yes & 3 & 5 & \multirow[t]{2}{*}{$0 \cdot 003$} \\
\hline No & 31 & 5 & \\
\hline \multicolumn{4}{|l|}{ Stage $\mathrm{e}^{\mathrm{e}}$} \\
\hline $1+I I$ & 22 & 2 & \multirow[t]{2}{*}{$0 \cdot 0096$} \\
\hline III+IV & 13 & 9 & \\
\hline \multicolumn{4}{|c|}{ Classic papillary histotype } \\
\hline Yes & 24 & 8 & \multirow[t]{2}{*}{1} \\
\hline No & 15 & 5 & \\
\hline \multicolumn{4}{|c|}{ Follicular variant histotype } \\
\hline Yes & 10 & 2 & \multirow[t]{2}{*}{$0 \cdot 44$} \\
\hline No & 29 & 11 & \\
\hline \multicolumn{4}{|c|}{ Other histotype } \\
\hline Yes & 5 & 3 & \multirow[t]{2}{*}{$0 \cdot 17$} \\
\hline No & 34 & 10 & \\
\hline \multicolumn{4}{|c|}{$\mathrm{B}-\mathrm{RAF}^{\mathrm{V} 600 \mathrm{E}}$ test } \\
\hline Positive & 20 & 7 & \multirow[t]{2}{*}{$0 \cdot 87$} \\
\hline Negative & 19 & 6 & \\
\hline
\end{tabular}

anformation was not available for one patient.

${ }^{\mathrm{b}}$ Information was not available for three patients.

${ }^{\mathrm{C}}$ Information was not available for two patients.

'Information was not available for eight patients.

e Information was not available for six patients.

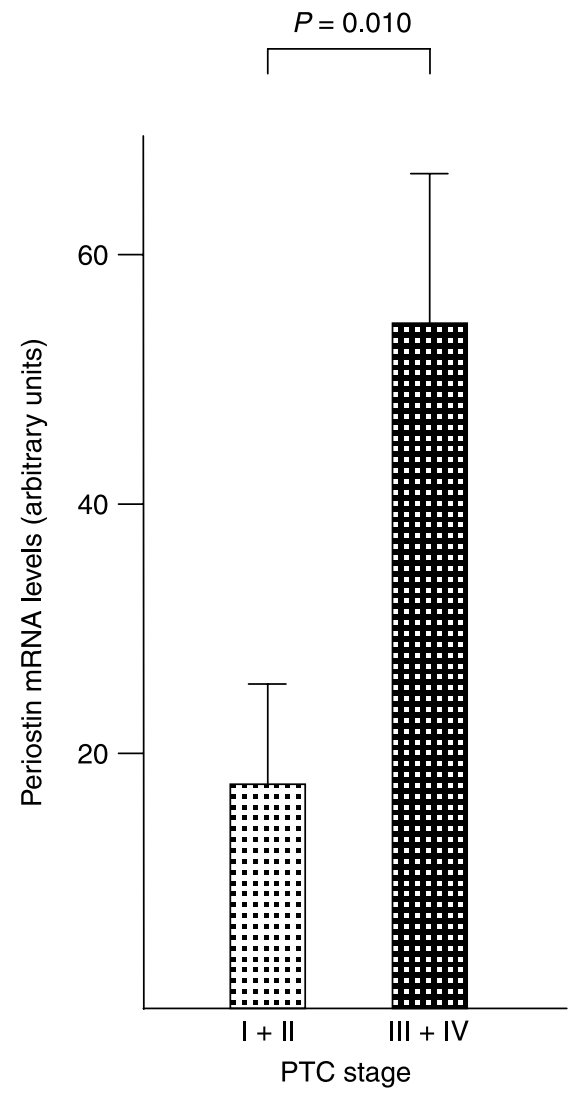

Figure 3 Periostin mRNA levels in papillary thyroid carcinomas according to the stage. Stages I+II, 32 cases; stages III + IV, 20 cases. Each bar indicates the mean value \pm s.D.

status and clinical parameters indicative of a worse prognosis (data not shown).

In 43 out of 52 samples, a comparative analysis of the two groups regarding the expression levels of some thyroid-specific genes showed a significant relationship $(P<0 \cdot 05)$ between the presence of high levels of periostin and low expression levels of $\mathrm{Tg}$ and $\mathrm{TSH}$ receptor genes (Table 2).

Table 2 Association between periostin and differentiation markers expression mRNA levels in tumors from 43 papillary carcinomas (PTCs)

\begin{tabular}{|c|c|c|c|}
\hline & $\begin{array}{l}\text { Periostin } \\
\text { expression }< \\
\text { mean }\end{array}$ & $\begin{array}{l}\text { Periostin } \\
\text { expression }> \\
\text { mean }\end{array}$ & $\boldsymbol{P}^{\mathrm{a}}$ \\
\hline \multicolumn{4}{|l|}{ Marker } \\
\hline NIS & $0 \cdot 068 \pm 0 \cdot 100$ & $0 \cdot 033 \pm 0 \cdot 058$ & $0 \cdot 18$ \\
\hline AIT-B & $0 \cdot 170 \pm 0 \cdot 276$ & $0 \cdot 070 \pm 0 \cdot 105$ & 0.09 \\
\hline TPO & $0 \cdot 254 \pm 0 \cdot 711$ & $0 \cdot 058 \pm 0 \cdot 093$ & $0 \cdot 12$ \\
\hline $\operatorname{Tg}$ & $0.445 \pm 0.325$ & $0 \cdot 241 \pm 0 \cdot 203$ & $0 \cdot 02$ \\
\hline TSHR & $0.707 \pm 0.474$ & $0.462 \pm 0.268$ & 0.04 \\
\hline
\end{tabular}

Results are expressed in arbitrary units, after normalization with the value found in normal tissue (considered as $1 \cdot 0$ ).

a Periostin $>$ mean tumors versus periostin $<$ mean tumors. 


\section{Periostin expression in thyroid cancer cell lines}

In order to find models to investigate the mechanisms underlying the increased periostin mRNA expression, we analyzed six different human thyroid cancer cell lines: BCPAP, TPC-1, and NPA (derived from PTC); WRO (derived from FTC); and ARO and FRO (derived from anaplastic thyroid carcinoma; Russo et al. 2001). Results are shown in Fig. 4A. Cell lines can be classified into two different groups: cells expressing periostin mRNA at high levels (BCPAP, WRO, and FRO) and cells expressing periostin at very low levels (NPA, TPC-1, and ARO). These data confirm the heterogeneity of periostin expression observed in human tumors. We then used BCPAP (high periostin expression) and TPC-1 (very low periostin expression) cell lines to ask whether the activity of the periostin promoter may correlate with the mRNA levels. To this purpose, a construct containing $563 \mathrm{bp}$ of periostin promoter (Oshima et al. 2002) was transfected and its activity measured in these cell lines. As shown in Fig. 4B, the periostin promoter activity is four to five times higher in BCPAP than in TPC-1. These results suggest that high levels of periostin $\mathrm{mRNA}$ observed in several PTCs could be due, at least in part, to increase in the periostin promoter activity.

\section{Discussion}

In normal tissues, periostin gene is expressed only in mesenchymal-originating cells (Kudo et al. 2007). However, several studies have demonstrated that the periostin gene can be expressed in tumors of epithelial origin. Such an abnormal expression may be related to the EMT occurring during malignant transformation of epithelial cells, as reported also for PTC (Vasko et al. 2007). A defining feature of the EMT is the gain of fibronectin and vimentin expression associated with the loss of E-cadherin expression (Hendrix et al. 1996, Shook \& Keller 2003). Epithelial-to-mesenchymal transdifferentiated epithelial cells lose cell-cell contact, modify the cytoskeleton, and manifest a migratory phenotype (Thiery \& Sleeman 2006). Thus, EMT may play a relevant role in the conversion of early stage to invasive malignancy (Lee et al. 2006, Horikawa et al. 2007). Periostin could play a causal role in EMT. In fact, stable induction of a periostin transgene in 293T cells causes EMT (Rios et al. 2005). Accordingly, both in human tumors and in experimental systems, periostin expression seems to be related to the aggressiveness of the neoplasm (Sasaki et al. 2001, 2003, Shao et al. 2004, Kudo et al. 2007).

Among thyroid carcinomas, periostin expression has been previously investigated only in a small study including ten well-differentiated PTCs and seven clinically aggressive PTCs (Fluge et al. 2006). Using quantitative RT-PCR, it has been shown that periostin expression had a median 30-fold overexpression in the aggressive PTCs and a median 4-fold overexpression in the differentiated PTC group. Thus,
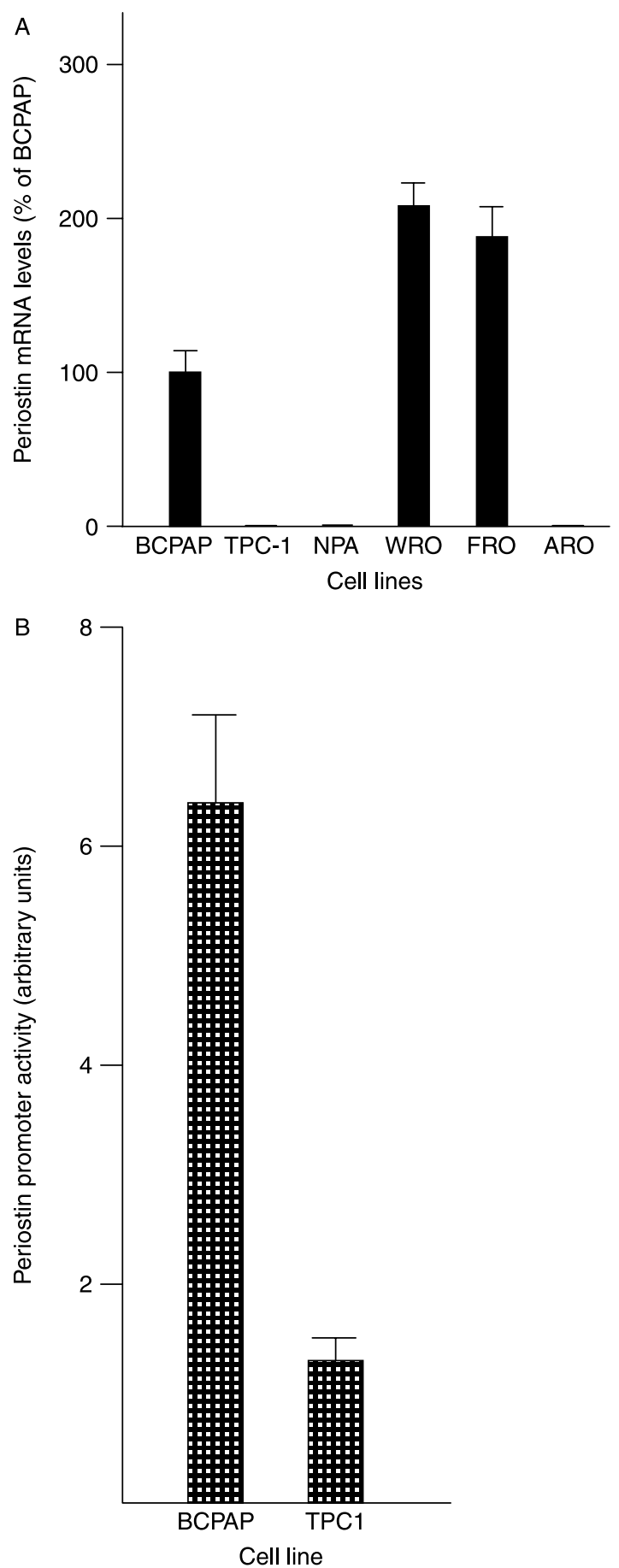

Figure 4 (A) Periostin mRNA levels in several human thyroid cell lines. Results are expressed as percentage of values obtained in the BCPAP cell line. Each bar indicates the mean value \pm s.D. obtained in three independent quantitative PCR measures. (B) Periostin promoter activity in BCPAP and TPC-1 cell lines. Results are expressed as arbitrary units and, for each cell line, represent the ratio between the periostin promoter and the RSV promoter, which has been used to normalize for efficiency of transfection. Each bar indicates the mean value \pm s.D. obtained in three independent transfection experiments. 
periostin gene overexpression was statistically correlated with the aggressiveness of the tumor. Global gene expression studies performed by SAGE or microarrays have not detected increase in periostin expression in thyroid carcinomas (Huang et al. 2001, Aldred et al. 2004, Jarzab et al. 2005, Cerutti et al. 2007, Delys et al. 2007, Fujarewicz et al. 2007, Rodrigues et al. 2007). These apparently negative results could be explained by technical reasons and by the particular study design (i.e., small number of patient investigated, no paired comparison between normal and tumoral tissues, analysis of low stages only). In order to look at raw data, we interrogated the Gene Expression Omnibus (GEO) database at the NCBI (http://www.ncbi.nlm.nih.gov/geo/). In about half of subjects whose both normal and tumor tissues have been investigated, a clear increase in periostin gene expression in the tumor is evident. However, neither the clinical characteristics of the tumors nor a confirmation of the data using other methodologies (i.e. RT-PCR or in situ hybridization) are reported.

The goal of our research was to investigate periostin expression in a large cohort of PTCs as well as in other differentiated thyroid neoplasms: FTC and benign FA. Moreover, in most cases, the tumor was matched to the normal tissue from the same patient. In agreement to Fluge et al. (2006), we found that in some PTCs periostin expression was much higher than the corresponding normal tissue. In addition, a correlation was found with various clinical/pathological features of PTCs, including the presence of extrathyroidal invasion, distant metastasis, and higher grade staging. This picture is consistent with the existence of a link between periostin expression, EMT, and an aggressive behavior of the tumor. Instead, as reported for other markers of EMT (Vasko et al. 2007), our data show that increased expression of periostin occurs regardless of the presence of a $B-R A F$ mutation, recently demonstrated as a marker of loss of differentiation (Durante et al. 2007). Thus, our data suggest that a high periostin expression level is a stronger indicator than B-RAF of a worse prognosis either in $B-R A F$ mutation positive or negative PTCs. Moreover, we also found a significant relationship between higher levels of periostin mRNA and lower levels of $\mathrm{Tg}$ and TSHR gene expression. The presence of these two proteins is a fundamental requisite for an optimal follow-up of the patients with PTC after thyroidectomy. These additional findings further support a correlation between periostin expression and molecular alterations underlying a more aggressive behavior of the tumors.

Severe growth retardation has been reported during postnatal life in periostin-deficient mice embryos (Rios et al. 2005), suggesting a role for periostin in the control of cell proliferation rather than differentiation. However, our present data on FAs seem to exclude the occurrence of abnormal expression of periostin as an early event of thyroid tumorigenesis. Instead, it appears to be related to the PTC phenotype, the thyroid cancer histotype in which the EMT has been described with higher frequency and associated with tumor aggressiveness (Vasko et al. 2007), as also confirmed by our data on FTCs.
As for other markers of EMT, therefore, periostin may represent a target for the future development of novel potential treatment of aggressive PTCs presenting such alteration. For this purpose, a central question is to clarify the molecular mechanisms responsible for the increase in periostin gene expression that was observed in some papillary thyroid tumors. Mechanisms responsible for periostin gene transcription have been recently investigated by analyzing the promoter region of the human periostin gene (Oshima et al. 2002, Lindsley et al. 2007). Our data indicate that the activity of the proximal periostin promoter is higher in the BCPAP cell line with respect to the TPC-1 cell lines, suggesting that among PTCs differences of periostin expression may be due, at least in part, to transcriptional mechanisms. The periostin promoter construct that we have used contains a sequence recognized by the transcription factor Twist (Oshima et al. 2002). This transcription factor plays a role in tumorigenesis (Puisieux et al. 2006) and its overexpression appears to play a relevant role in EMT (Huber et al. 2005). Thus, Twist overexpression may have a critical role in thyroid tumor progression. Further knowledge of the molecular mechanisms underlying aberrant expression of periostin gene in thyroid tumors may provide new hints for better characterization of the more aggressive PTCs, still refractory to present treatments.

\section{Acknowledgements}

This work is funded by grants from Regione Friuli VeneziaGiulia and MIUR to G D and D R and by grants from the Fondazione Umberto Di Mario to S F. C P is supported by a grant FIRC (Federazione Italiana Ricerca Cancro). We thank Dr Kudo for the gift of the plasmid containing the periostin promoter activity. The authors declare that there is no conflict of interest that would prejudice the impartiality of this scientific work.

\section{References}

Aldred MA, Huang Y, Liyanarachchi S, Pellegata NS, Gimm O, Jhiang S, Davuluri RV, de la Chapelle A \& Eng C 2004 Papillary and follicular thyroid carcinomas show distinctly different microarray expression profiles and can be distinguished by a minimum of five genes. Journal of Clinical Oncology 22 3531-3539.

Bao S, Ouyang G, Bai X, Huang Z, Ma C, Liu M, Shao R, Anderson RM, Rich JN \& Wang XF 2004 Periostin potently promotes metastatic growth of colon cancer by augmenting cell survival via the Akt/PKB pathway. Cancer Cell 5 329-339.

Beillard E, Pallisgaard N, van der Velden VH, Bi W, Dee R, van der Schoot E, Delabesse E, Macintyre E, Gottardi E, Saglio G et al. 2003 Evaluation of candidate control genes for diagnosis and residual disease detection in leukemic patients using 'real-time' quantitative reverse-transcriptase polymerase chain reaction (RQ-PCR) - a Europe against cancer program. Leukemia 17 2474-2486.

Brabant G, Maenhaut C, Köhrle J, Scheumann G, Dralle H, Hoang-Vu C, Hesch RD, von zur Mühlen A, Vassart G \& Dumont JE 1991 Human thyrotropin receptor gene expression in thyroid tumors and correlation to markers of thyroid differentiation and dedifferentiation. Molecular and Cellular Endocrinology 82 7-12. 
Cerutti JM, Oler G, Michaluart P, Jr, Delcelo R, Beaty RM, Shoemaker J \& Riggins GJ 2007 Molecular profiling of matched samples identifies biomarkers of papillary thyroid carcinoma lymph node metastasis. Cancer Research 67 7885-7892.

Damante G, Tell G \& Di Lauro R 2001 A unique combination of transcription factors controls differentiation of thyroid cells. Progress in Nucleic Acid Research and Molecular Biology 66 307-356.

Delys L, Detours V, Franc B, Thomas G, Bogdanova T, Tronko M, Libert F, Dumont JE \& Maenhaut C 2007 Gene expression and the biological phenotype of papillary thyroid carcinomas. Oncogene 26 7894-7903.

Durante C, Puxeddu E, Ferretti E, Morisi R, Moretti S, Bruno R, Barbi F, Avenia N, Scipioni A, Verrienti A et al. 2007 B-RAF mutations in papillary thyroid carcinomas inhibit genes involved in iodine metabolism. Journal of Clinical Endocrinology and Metabolism 92 2840-2843.

Fabbro D, Di Loreto C, Beltrami CA, Belfiore A, Di Lauro R \& Damante G 1994 Expression of thyroid-specific transcription factors TTF-1 and PAX-8 in human thyroid neoplasms. Cancer Research 54 4744-4749.

Fluge Ø, Bruland O, Akslen LA, LillehaugJR \& VarhaugJE 2006 Gene expression in poorly differentiated papillary thyroid carcinomas. Thyroid 16 161-175.

Fujarewicz K, Jarzab M, Eszlinger M, Krohn K, Paschke R, OczkoWojciechowska M, Wiench M, Kukulska A, Jarzab B \& Swierniak A 2007 A multi-gene approach to differentiate papillary thyroid carcinoma from benign lesions: gene selection using support vector machines with bootstrapping. Endocrine-Related Cancer 14 809-826.

Gillan L, Matei D, Fishman DA, Gerbin CS, Karlan BY \& Chang DD 2002 Periostin secreted by epithelial ovarian carcinoma is a ligand for alpha(V)beta(3) and alpha(V)beta(5) integrins and promotes cell motility. Cancer Research 62 5358-5364.

Greene FL, Page DL, Fleming ID, Fritz AG, Balch CM, HallerDG \& Morrow M 2002 American Joint Committee on Cancer. In AJCC Cancer Staging Manual, edn 6, pp 77-87. Berlin: Springer \& Verlag.

Hendrix MJ, Seftor EA, Chu YW, Trevor KT \& Seftor RE 1996 Role of intermediate filaments in migration, invasion and metastasis. Cancer and Metastasis Reviews 15 507-525.

Horikawa T, Yang J, Kondo S, Yoshizaki T, Joab I, Furukawa M \& Pagano JS 2007 Twist and epithelial-mesenchymal transition are induced by the EBV oncoprotein latent membrane protein 1 and are associated with metastatic nasopharyngeal carcinoma. Cancer Research 67 1970-1978.

Horiuchi K, Amizuka N, Takeshita S, Takamatsu H, Katsuura M, Ozawa H, Toyama Y, Bonewald LF \& Kudo A 1999 Identification and characterization of a novel protein, periostin, with restricted expression to periosteum and periodontal ligament and increased expression by transforming growth factor beta. Journal of Bone and Mineral Research 14 1239-1249.

Huang Y, Prasad M, Lemon WJ, Hampel H, Wright FA, Kornacker K, LiVolsi V, Frankel W, Kloos RT, Eng C et al. 2001 Gene expression in papillary thyroid carcinoma reveals highly consistent profiles. PNAS 98 15044-15049.

Huber MA, Kraut N \& Beug H 2005 Molecular requirements for epithelialmesenchymal transition during tumor progression. Current Opinion in Cell Biology 17 548-558.

Jarzab B, Wiench M, Fujarewicz K, Simek K, Jarzab M, OczkoWojciechowska M, Wloch J, Czarniecka A, Chmielik E, Lange D et al. 2005 Gene expression profile of papillary thyroid cancer: sources of variability and diagnostic implications. Cancer Research 65 1587-1597.

Kudo Y, Siriwardena BS, Hatano H, Ogawa I \& Takata T 2007 Periostin: novel diagnostic and therapeutic target for cancer. Histology and Histopathology 22 1167-1174.

Lee TK, Man K, Poon RT, Lo CM, Yuen AP, Ng IO, Ng KT, Leonard W \& Fan ST 2006 Signal transducers and activators of transcription $5 \mathrm{~b}$ activation enhances hepatocellular carcinoma aggressiveness through induction of epithelial-mesenchymal transition. Cancer Research 66 9948-9956.

Lindsley A, Snider P, Zhou H, Rogers R, Wang J, Olaopa M, KruzynskaFrejtag A, Koushik SV, Lilly B, Burch JB et al. 2007 Identification and characterization of a novel Schwann and outflow tract endocardial cushion lineage-restricted periostin enhancer. Developmental Biology 307 340-355.
Oshima A, Tanabe H, Yan T, Lowe GN, Glackin CA \& Kudo A 2002 A novel mechanism for the regulation of osteoblast differentiation: transcription of periostin, a member of the fasciclin I family, is regulated by the bHLH transcription factor, twist. Journal of Cellular Biochemistry 86 792-804.

Puisieux A, Valsesia-Wittmann S \& Ansieau S 2006 A twist for survival and cancer progression. British Journal of Cancer 94 13-17.

Puppin C, D'Aurizio F, D'Elia AV, Cesaratto L, Tell G, Russo D, Filetti S, Ferretti E, Tosi E, Mattei T et al. 2005 Effects of histone acetylation on sodium iodide symporter promoter and expression of thyroid-specific transcription factors. Endocrinology 146 3967-3974.

Puxeddu E, Moretti S, Elisei R, Romei C, Pascucci R, Martinelli M, Marino C, Avenia N, Rossi ED, Fadda G et al. 2004 BRAF(V599E) mutation is the leading genetic event in adult sporadic papillary thyroid carcinomas. Journal of Clinical Endocrinology and Metabolism 89 2414-2420.

Rios H, Koushik SV, Wang H, Wang J, Zhou HM, Lindsley A, Rogers R, Chen Z, Maeda M, Kruzynska-Frejtag A et al. 2005 Periostin null mice exhibit dwarfism, incisor enamel defects, and an early-onset periodontal disease-like phenotype. Molecular and Cellular Biology 25 11131-11144.

Rodrigues RF, Roque L, Krug T \& Leite V 2007 Poorly differentiated and anaplastic thyroid carcinomas: chromosomal and oligo-array profile of five new cell lines. British Journal of Cancer 96 1237-1245.

Ros P, Rossi DL, Acebron A \& Santisteban P 1999 Thyroidspecific gene expression in the multi-step process of thyroid carcinogenesis. Biochimie 81 389-396.

Russo D, Arturi F, Bulotta S, Pellizzari L, Filetti S, Manzini G, Damante G \& Tell G 2001 ApeI/Ref-I expression and cellular localization in human thyroid carcinoma cell lines. Journal of Endocrinological Investigation 24 10-12.

Sasaki H, Dai M, Auclair D, Fukai I, Kiriyama M, Yamakawa Y, Fujii Y \& Chen LB 2001 Serum level of the periostin, a homologue of an insect cell adhesion molecule, as a prognostic marker in nonsmall cell lung carcinomas. Cancer 92 843-848.

Sasaki H, Yu CY, Dai M, Tam C, Loda M, Auclair D, Chen LB \& Elias A 2003 Elevated serum periostin levels in patients with bone metastases from breast but not lung cancer. Breast Cancer Research and Treatment 77 245-252.

Schlumberger M, Lacroix L, Russo D, Filetti S \& Bidart JM 2007 Defects in iodide metabolism in thyroid cancer and implications for the follow-up and treatment of patients. Nature Clinical Practice. Endocrinology and Metabolism 3 260-269.

Shao R, Bao S, Bai X, Blanchette C, Anderson RM, Dang T, Gishizky ML, Marks JR \& Wang XF 2004 Acquired expression of periostin by human breast cancers promotes tumor angiogenesis through up-regulation of vascular endothelial growth factor receptor 2 expression. Molecular and Cellular Biology 24 3992-4003.

Shook D \& Keller R 2003 Mechanisms, mechanics and function of epithelialmesenchymal transitions in early development. Mechanisms of Development 120 1351-1383.

Takeshita S, Kikuno R, Tezuka K \& Amann E 1993 Osteoblast-specific factor 2: cloning of a putative bone adhesion protein with homology with the insect protein fasciclin I. Biochemical Journal 294 271-278.

Thiery JP \& Sleeman JP 2006 Complex networks orchestrate epithelialmesenchymal transitions. Nature Reviews. Molecular Cell Biology 7 131-142.

Vasko V, Espinosa AV, Scouten W, He H, Auer H, Liyanarachchi S, Larin A, Savchenko V, Francis GL, de la Chapelle A et al. 2007 Gene expression and functional evidence of epithelial-to-mesenchymal transition in papillary thyroid carcinoma invasion. PNAS 104 2803-2808.

Zhang Z \& Xie FP 1994 Transdifferentiation of neoplastic cell. Foreign Medical Science (Oncology) 21 8-9.

Received in final form 1 February 2008

Accepted 11 February 2008

Made available online as an Accepted Preprint 11 February 2008 